\title{
Equilibrium, kinetic and thermodynamic studies on the adsorption of atrazine in soils of the water fluctuation zone in the Three-Gorges Reservoir
}

\author{
Haiyan Yu', Yongfeng Liu' ${ }^{1}$, Xingquan Shu' ${ }^{1}$, Han Fang ${ }^{1}$, Xiaojing Sun ${ }^{1}$, Yuwei Pan² and Limin Ma ${ }^{1,3^{*}}$ (1)
}

\begin{abstract}
Background: Environmental behavior of pesticide in soils is a key current research focus. Studying the adsorption characteristics of pesticides in soils as a parameter for evaluating the risk of groundwater pollution by pesticides is commonly applied in agriculture.

Results: To provide a theoretical basis for environment risk assessment and pollution remediation, the thermodynamics and kinetics of the equilibrium of atrazine adsorption in the Three-Gorges Reservoir area were assessed and analyzed via batch experiments. Results showed that the sorption of atrazine was an exothermic and spontaneous process at temperatures of 298-318 K. Atrazine was more easily adsorbed by soils at concentrations of 0-30 $\mathrm{mg} \mathrm{L}^{-1}$, with low-temperature adsorption being more effective than high-temperature adsorption. The adsorption of atrazine to the two assessed soils was well fitted by the Freundlich and Langmuir models. The adsorption kinetics of atrazine in soils were consistent with the quasi-second-order kinetic model and intraparticle diffusion was found not to be the only control step. The monolayer adsorption occurred with non-uniform energy distribution on the soil surface, indicating that the adsorption of atrazine by the two kinds of soil was controlled by internal diffusion surface adsorption and liquid film diffusion, leading to the complexity of its adsorption kinetics. The values of standard free energy $\Delta r G_{m}^{0}<0$, indicated that the adsorption of atrazine in soils was spontaneous and dominated by physical adsorption. Changes in standard enthalpy $\left(\Delta \mathrm{r} H_{m}^{0}\right)$ indicated that the adsorption was exothermic.
\end{abstract}

Conclusions: Atrazine exhibited a weak adsorption capacity in both soils, indicating it is highly mobile in the soilwater environment and can easily cause groundwater pollution. Therefore, much attention should be paid to the environmental behavior of pesticide soil moisture fluctuations, potentially leading to the broad transfer and spread of pollution.

Keywords: Soil, Atrazine, Water fluctuation zone, Kinetics, Sorption, Thermodynamics

\section{Background}

Pesticides are widely used in agriculture to increase crop yields and quality [1]. Atrazine is one of the most widely used pesticides worldwide, being a long-term and

\footnotetext{
${ }^{*}$ Correspondence: Imma@tongji.edu.cn

${ }^{1}$ College of Environmental Science and Engineering, Tongji University,

Shanghai 200092, China

Full list of author information is available at the end of the article
}

large-area herbicide suitable for the removal of broadleaved weed species [2-5]. Long-term atrazine residue accumulation in the soil accounts for $20 \%-70 \%$ of the applied dose during application and is one of the most commonly detected pesticides in soils and groundwater worldwide [6-8]. However, atrazine is one of the triazine herbicides which was banned by the European Union in 2004 (2004/248/EC) [9] and was added to the list of 
priority substances (Directive 2013/39/EU) [10]. In recent years, atrazine and its decomposition intermediates have been regularly detected in groundwaters, lakes and bays in many countries $[5,11,12]$. Due to the persistence, high-water solubility and hazard associated with atrazine pollution, its large-scale and excessive use in agriculture presents a serious risk to both environmental and human health [12-14]. It has been reported that atrazine affects human immune, endocrine and reproductive systems; while in severe cases, it may lead to malformations and induce mutations, which are potentially carcinogenic to humans $[4,5,15,16]$. Therefore, atrazine's environmental behavior, particularly its transportation and fate, has received extensive research interest $[7,16,17]$.

Atrazine undergoes a series of processes after entering the soil, such as soil adsorption-desorption, degradation, and crop absorption due to surface runoff and eluviation in surface and groundwater systems. Among these, adsorption-desorption is one of the key factors affecting atrazine's migration and transformation in the environment and, thus, directly affects the efficiency of atrazine pollution prevention and remediation strategies $[18,19]$. The adsorption behavior of atrazine in soil is also a key factor affecting the distribution, migration, bioavailability and toxicity of pollutants in soil, which has an important impact on the fate of pollutants in the environment [20-23]. Thus, the adsorption mechanism and influencing factors between pesticides and different soils have always been the focus of environmental studies [24]. There are many available studies on the adsorption, leaching and migration of atrazine in soils of different texture types, including paddy soil, black soil and loess soil, as well as the sorption and desorption processes [21, 25-28]. Studies have shown that the adsorption process of organic compounds is complex and affected by many factors, including $\mathrm{pH}$, cation exchange capacity, surface area of the sorbent and ionic strength [29,30]. However, the adsorption kinetics and thermodynamic properties of atrazine in different soils remain unclear and further research is needed especially on the adsorption mechanisms of atrazine in soils of water fluctuation zones. The adsorption of atrazine in soils in different environments has been shown to vary significantly $[30,31]$. Therefore, it is important to study the adsorption behavior of atrazine in different soils, to analyze and evaluate the fate and risk of environmental migration and provide a reference for the treatment and control of atrazine pollution in soil $[21,30]$.

The water fluctuation zone of a large reservoir is a combined land and water ecosystem, which varies within ecosystems in a cycle of alternating irrigation and drainage and is strongly disturbed by human activities [32, 33]. The Three-Gorges Reservoir in China is a representative example with a vertical depth of $30 \mathrm{~m}$ and a total area of over $300 \mathrm{~km}^{2}$ [34]. The water fluctuation zone of the Three-Gorges Reservoir is a traditional crop planting area. Agricultural production activities use a large amount of pesticides to increase production, which subsequently transfer to the soil. The absorbed pesticides in the soil are desorbed into the reservoir water body and serious environmental pollution caused by the release of pollutants from the soil becomes inevitable. Therefore, the purpose of this study was to investigate the adsorption mechanism and thermodynamics of atrazine in soils with a high intensity of anthropogenic activity, assessing the effect of parameters such as temperature and contact time. These results will help to better understand the dynamics and thermodynamics of atrazine adsorption processes, while providing methods for protecting drinking water resources from contamination and predicting the fate, transport and risk assessment of atrazine in the environment.

\section{Materials and methods \\ Soils}

The assessed soil samples were collected from the bank of the Yangzi River from Wanzhou to Wushan in Chongqing, within the water fluctuation zone of the ThreeGorges Reservoir. The collected fresh soil samples were taken from the layer at a depth of $0-20 \mathrm{~cm}$, naturally dried at room temperature, homogenized, with the removal of stones, plant roots and other non-soil debris, before being passed through a 2 -mm mesh sieve for later use. The $\mathrm{pH}$ value was measured using a $\mathrm{pH}$ meter. Organic matter was treated by external heating with potassium dichromate. Soil particle size composition was determined via a Laser particle size analyzer (NKT6100, Shandong Nikeite Analytical Instrument Co., Ltd., Shandong, China). The cation exchange capacity (CEC) in soil was determined by cobalt extraction with hexaammonia trichloride by spectrophotometry (HJ 889-2017). The specific methods applied have previously been reported and all analyses were performed according to the previously reported methods without modification [35]. The measured properties of soils are outlined in Table 1.

\section{Chemicals}

The atrazine standard had a purity of $>99.9 \%$ (Dr. Ehrenstofer company; Germany), with the properties of atrazine outlined in Table 2. Methanol and acetonitrile were of chromatographic purity (China pharmaceutical group chemical reagent Co. Ltd., Shanghai, China). All other reagents were of analytical purity (ANPEL Scientific Instrument, Shanghai, Co., Ltd.). Ultrapure water was prepared using a Pulfil DZG-303A ultra-pure water system (Fusite instrument equipment co., Ltd., Shanghai). 
Table 1 Physical and chemical properties of soil samples

\begin{tabular}{lllllll}
\hline Soil sample site & pH & SOM (\%) & Clay (\%) & Silt (\%) & Sand (\%) & CEC (cmol kg $\left.\mathbf{~}^{\mathbf{- 1}}\right)$ \\
\hline Wanzhou & 6.85 & 2.27 & 22.58 & 42.19 & 35.23 & 17.5 \\
Wushan & 8.08 & 2.22 & 25.06 & 34.91 & 40.03 & 8.24 \\
\hline
\end{tabular}

Table 2 Selected physicochemical characteristics of Atrazine

\begin{tabular}{l}
\hline Properties \\
\hline Molecular structure
\end{tabular}

\section{Sorption experiments}

Quantification of the sorption of atrazine in the two different soils was performed following the standard batch equilibrium method. Atrazine was weighed and dissolved in methanol, with a mole fraction of less than 0.001 used to prepare the pesticide solution. Studies have previously reported that methanol has no effect on adsorption [36-39]. Experiments were carried out in $50-\mathrm{mL}$ polyethylene centrifuge tubes by adding $2.0 \mathrm{~g}$ of soil samples to $10-\mathrm{mL}$ solutions containing different atrazine concentrations $\left(0-30 \mathrm{mg} \mathrm{L}^{-1}\right)$. During experiments, $0.01 \mathrm{~mol}$ calcium chloride was used as the background electrolyte of the soil solution, to minimize the change in ionic strength and contribute to the separation of solid and aqueous solutions after equilibrium. The centrifuge tube was shaken for $48 \mathrm{~h}$ at a constant speed of $200 \mathrm{r} \mathrm{min}^{-1}$ in a thermostatic vibrating screen, with the adsorption equilibrium reached at temperatures of 298,308 , and $318 \mathrm{~K}$, respectively, and then centrifuged for $30 \mathrm{~min}$ at the same temperature. The same method was used for the blank experiment, without atrazine being added. Preliminary experiments have shown that the adsorption of pesticides to test tubes was negligible. The supernatant was collected and passed through a 0.45 -um micron filter; then, the atrazine content was measured by HPLC. The equilibrium adsorption capacity $q_{e}\left(\mathrm{mg} \mathrm{kg}^{-1}\right)$ of atrazine was calculated as follows in Eq. (1):

$$
q_{e}=\frac{\left(C_{0}-C_{e}\right) \times V}{m},
$$

where $V$ represents the volume of solutions (L); $C_{0}$ is the initial concentration of atrazine; $C_{e}\left(\mathrm{mg} \mathrm{L}^{-1}\right)$ is the equilibrium concentration of the adsorbate at time $t$ ( $\mathrm{min}) ; m$ is the mass of adsorbent $(\mathrm{g}) ; q_{e}\left(\mathrm{mg} \mathrm{kg}^{-1}\right)$ is the amount of atrazine adsorbed on soil.

All kinetic experiments were carried out at $25^{\circ} \mathrm{C}$ under normal ambient pressures. A 2.0-g soil sample was placed in a $50-\mathrm{mL}$ bottle containing $10-\mathrm{mL}$ atrazine solution at a concentration of $30 \mathrm{mg} \mathrm{L}^{-1}$ and stirred using a constant temperature shaker. Samples were taken at set intervals and three repetitions were performed for each treatment. The supernatant was centrifuged at $8000 \mathrm{rpm}$ for $5 \mathrm{~min}$ and then passed through a $0.45-\mu \mathrm{m}$ micron filter for later use.

\section{HPLC analysis}

The concentrations of atrazine in soil samples were analyzed by HPLC (Agilent 1200), using an ACE Excle $5 \mathrm{C}_{18}$ analytical column $(5 \mu \mathrm{m}, 250 \times 4.6 \mathrm{~mm}$, Phenomenex, Guangzhou, China). HPLC analyses were performed using mobile phase elution with $40 \%(\mathrm{v} / \mathrm{v})$ ultrapure water and $60 \%(\mathrm{v} / \mathrm{v})$ acetonitrile and an ultraviolet detector to monitor the absorbance of atrazine at $220 \mathrm{~nm}$.

\section{Results and discussion Adsorption isotherms}

To understand the interactions between atrazine and soil, as well as revealing the adsorption mechanism, adsorption isotherms were quantitatively established to analyze the process of atrazine transfer from the solid phase to the liquid phase [40]. The adsorption isotherm of atrazine in both soils was depicted at different temperatures, as shown in Fig. 1. Results revealed that the adsorption capacity of atrazine was significantly different in the two soils, which might be attributed to the difference in physical and chemical properties between the two soils $[21,29,30]$. The adsorption curves for atrazine in the two soils were both L-type, with absorption increasing sharply initially and then showing a gradually increasing trend at 288, 298 and $308 \mathrm{~K}$ (Fig. 1a, b). For each isotherm, the soil equilibrium adsorption capacity increased with increasing equilibrium concentration, due to the adsorption driving force increasing with the enhancement of equilibrium concentration [41]. The adsorption capacity of soil to atrazine decreased with the increase 

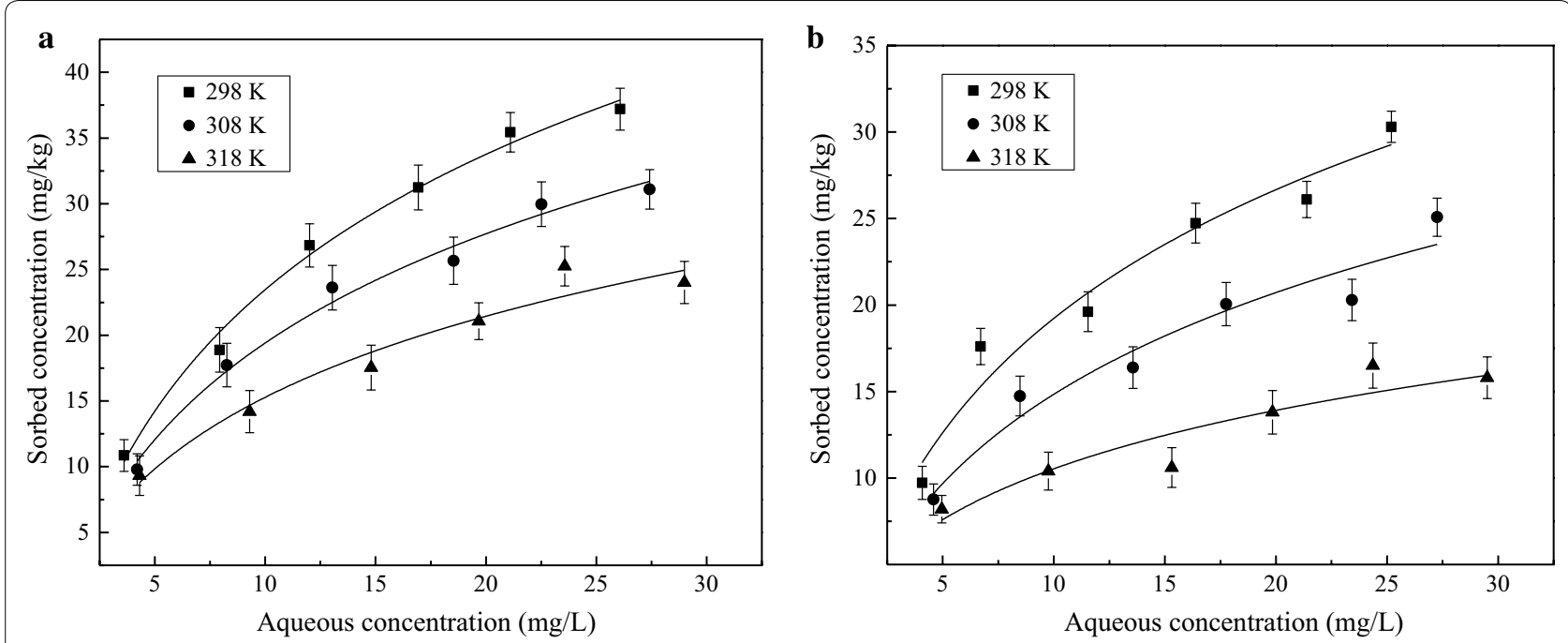

Fig. 1 Adsorption isotherms for atrazine in soils, based on two soils at different temperatures

in temperature within an initial atrazine concentration range from 0 to $30 \mathrm{mg} \mathrm{L}^{-1}$, especially in the Wushan soil (Fig. 1b). In addition, the equilibrium adsorption capacity also decreased with increasing temperature, suggesting that the atrazine adsorption process in the two soils was an exothermic process [26]. Generally, the adsorption capacity of atrazine in both soils was not very large, demonstrating that atrazine can easily penetrate the soil vadose zone and pollute groundwater.

The adsorption mechanism of atrazine in soil is likely to be related to soil properties. Monolayer sorption and heterogeneous energetic distribution of active sites on the surface of the soils were possible during the sorption process [41]. In the assessed range of atrazine concentrations, soil adsorption of atrazine exhibited a basic linear relationship, indicating that atrazine mainly adsorbs to soil organic matter via hydrophobic effects [42]. This type of distribution function is mainly related to the composition of soil organic matter and soil characteristics: (1) hydrogen bonds are formed between the neutral atrazine molecules and active centers on the surface of soil colloids; (2) ionic atrazine adsorbs on colloidal surfaces such as soil organic polyelectrolyte clay minerals; and (3) atrazine can form complexes with carboxyl groups and free hydroxyl groups in soil humic acid on the surface of soil colloidal micelles $[26,43]$. Therefore, adsorption models have been further used to analyze the mechanism of adsorption.

Linear, Friedrich or Langmuir adsorption models have commonly been used to describe analytical adsorption isotherms [44]. To clarify the overall adsorption process of atrazine in the two soils, Langmuir and Freundlich sorption models have been used. The Langmuir isotherm model [45] assumes that the energy adsorbed on the surface of the adsorbent is uniform, the adsorbent does not migrate in the surface plane and there is no interaction between the adsorbed molecules [46, 47], the equation for which is described as follows in Eq. (2):

$$
q_{e}=\frac{K_{L} q_{m} C_{e}}{1+K_{L} C_{e}},
$$

where $q_{e}$ is the amount of atrazine adsorbed by soil $\left(\mathrm{mg} \mathrm{kg}^{-1}\right) ; q_{m}$ is the maximum amount of atrazine adsorbed $\left(\mathrm{mg} \mathrm{kg}^{-1}\right) ; K_{L}\left(\mathrm{~L} \mathrm{mg}^{-1}\right)$ is a constant related to the adsorption energy; and $C_{e}$ is the equilibrium concentration of atrazine $\left(\mathrm{mg} \mathrm{L}^{-1}\right)$.

The Freundlich isotherm model is used to describe heterogeneous surface equations such as the heterogeneity of the adsorbent surface, the adsorption energy and the exponential distribution of the adsorption point. The adsorption data fit the Freundlich isotherm [48] and its expression is described in Eq. (3) as follows:

$$
q_{e}=K_{F} C_{e}^{1 / n},
$$

where $K_{F}$ and $\mathrm{n}$ are the Freundlich constants that refer to relative capacity and adsorption intensity, respectively.

The Freundlich and Langmuir models were used to fit the adsorption data of atrazine in soil, with the parameters depicted in Table 3. In all cases, the correlation coefficient $\left(R^{2}\right)$ of the Langmuir and Freundlich isotherm models exceeded 0.99, indicating that both models fit well to the adsorption of atrazine in both soil samples. According to the Freundlich model adsorption constant $\left(K_{F}\right)$, the adsorption capacity of the Wanzhou soil to atrazine was higher than Wushan soil and according to the Langmuir model, the sorption capacities $\left(q_{m}\right)$ of Wanzhou soil were higher than that 
Table 3 Freundlich and Langmuir isotherm constants for atrazine sorption in the assessed soil samples

\begin{tabular}{|c|c|c|c|c|c|c|c|}
\hline \multirow[t]{2}{*}{ Samples } & \multirow[t]{2}{*}{$T(K)$} & \multicolumn{3}{|c|}{ Freundlich } & \multicolumn{3}{|c|}{ Langmuir } \\
\hline & & $K_{F}$ & $N$ & $R^{2}$ & $Q_{\max }$ & $K_{L}$ & $R^{2}$ \\
\hline \multirow[t]{3}{*}{ Wanzhou soil } & 298 & 2.05 & 1.55 & 0.988 & 63.69 & 0.056 & 0.998 \\
\hline & 308 & 1.55 & 1.17 & 0.994 & 55.87 & 0.037 & 0.989 \\
\hline & 318 & 1.31 & 1.14 & 0.996 & 32.89 & 0.040 & 0.992 \\
\hline \multirow[t]{3}{*}{ Wushan soil } & 298 & 1.77 & 1.49 & 0.981 & 48.07 & 0.066 & 0.995 \\
\hline & 308 & 1.36 & 1.13 & 0.993 & 34.60 & 0.075 & 0.997 \\
\hline & 318 & 1.02 & 1.08 & 0.988 & 17.79 & 0.162 & 0.993 \\
\hline
\end{tabular}

of Wushan soil, which is consistent with the change in $K_{F}$. These results also demonstrate that the adsorption mechanism of atrazine in soil is related to both physical and chemical properties of the soil $[18,41]$.

The $q_{m}$ of the atrazine adsorbed by Wanzhou soil and Wushan soil decreased with increasing temperature, suggesting that the adsorption amount was negatively correlated with temperature. For the Freundlich model, $n<1$ represents unfavorable absorption conditions and $n>1$ represents favorable sorption conditions. In this study, the lowest $n$ values for atrazine adsorbed by Wushan soil at the three temperatures of 298, 308, and $318 \mathrm{~K}$ were $1.49,1.13$, and 1.07 , respectively. The $\mathrm{n}$ values were greater than 1 in all experiments, suggesting that sorption in both soil samples were favorable. The atrazine $K_{F}$ value for soil adsorption decreased with increasing temperature from 298 to $318 \mathrm{~K}$. Moreover, the values of $K_{F}$ were less than 5 in all experiments, implying that atrazine has a weak adsorption capacity in these two soils, that atrazine is highly mobile in the soil-water environment and likely to cause groundwater pollution $[27,49]$.

Based on further analysis of the Langmuir equation, the dimensionless parameter of the equilibrium or sorption intensity $\left(R_{L}\right)$ was calculated using Eq. (4) as follows $[50,51]$ :

$$
R_{L}=\frac{1}{1+K_{L} C_{0}}
$$

where $C_{0}$ is the initial concentration of atrazine $\left(\mathrm{mg} \mathrm{L}^{-1}\right)$. The change in soil adsorption strength $\left(R_{L}\right)$ indicates the type of isotherm and adsorption state, as per the following classification criteria: $R_{L}>1$ indicates unfavorable adsorption; $R_{L}=1$ indicates linear adsorption; $0<R_{L}<1$ indicates favorable adsorption; $R_{L}=0$ indicates irreversible adsorption $[50,52]$.

In this study, the $R_{L}$ values for atrazine adsorption by Wanzhou soils were $0.37,0.47$ and 0.45 ; while for Wushan soils, they were $0.33,0.31$, and 0.17 at 298, 308, and $318 \mathrm{~K}$, respectively. The $R_{L}$ values for atrazine indicate that it could be well adsorbed by the two assessed soils. With increasing temperatures, the reaction rate decreased, indicating that the adsorption of atrazine in low temperature environments was easier than in high-temperature environments. Results imply that the two soils have a certain affinity for atrazine, but absorption was negatively correlated with temperature [49]. In addition, low-temperature conditions can promote the adsorption of atrazine in both soil samples, which is consistent with the results of the Freundlich model.

\section{Adsorption kinetics}

Adsorption kinetics are one of the main properties controlling the absorption rate and adsorption efficiency of solutes and are highly valuable when revealing the migration and transformation rate of atrazine in soil environments [27]. In this study, we used adsorption kinetics to assess the effects and dynamics of contact time on the adsorption capacity of atrazine in the two soil samples as shown in Fig. 2. As shown, the adsorption kinetics of atrazine in the two soils were similar, with both undergoing distinct stages of rapid adsorption, slow adsorption and equilibrium adsorption. Within $60 \mathrm{~min}$, the adsorption rate of atrazine in the both soils was increased and

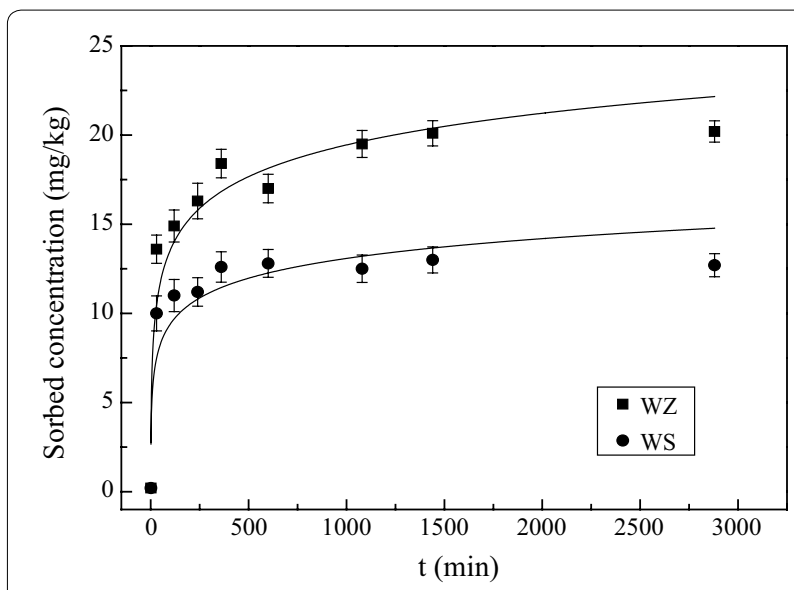

Fig. 2 Effect of contact time on the sorption capacity of atrazine in soil samples. WZ Wanzhou soil, WS Wushan soil 
the adsorption capacity showed a sharp increase because of physical adsorption to mineral surfaces $[49,53]$. The faster initial sorption rate might be attributed to chemical bonds and hydrogen bonds between the atrazine and minerals [24]. With an increase in contact time, the adsorption rate decreased and the adsorption process gradually approached equilibrium within $48 \mathrm{~h}$. The reason for this phenomenon may be due to the high initial atrazine concentration increasing the molecular collision frequency, allowing the dissolved state atrazine molecules to rapidly adsorb onto the surface of soil particles. In contrast, the molecular collision frequency decreased with low initial atrazine concentrations, resulting in a slower adsorption rate [26]. In addition, the rapid adsorption phase of atrazine to soil was determined by the large pores on the surface of particles; while, the slow adsorption phase was determined by micropores inside the soil particles. Slow adsorption processes may be related to the region where organic compounds gradually enter soil micropores or where soil organic matter is highly crosslinked, covering the adsorption sites on the internal surfaces of minerals [54]. This phenomenon is compatible with the reported results of adsorption reactions of organic pollutants on porous media particles, showing the reaction can generally be divided into a rapid reaction phase and a slow reaction phase [55].

The adsorption process of atrazine to soils is complicated, as a result of the interactions between organic matter and inorganic minerals in soil $[24,56]$. The rapid adsorption of organic pollutants can be attributed to their distribution in soil organic matter and on the surface of minerals. Physical adsorption in terms of the intermolecular interaction force is mainly manifested by the van der Waals force, dipole force, and hydrogen bonding force, with these effects usually completed in a relatively short time period [43]. To reach the adsorption site on the surface of soil particles, hydrophobic organic pollutants need to overcome the diffusion of water molecules on the surface of soil particles into soil micropores and diffuse into the pores of the soil particles through the matrix $[43,57]$. The rapid adsorption process of atrazine mainly occurs due to the presence of organic matter contained in the soil, as well as the distribution and physical adsorption of the mineral surface [43].

To describe the characteristics and mechanism of atrazine adsorption in soil, a pseudo-second-order kinetic model was employed, which can be described according to Eq. (5) as follows [58]:

$$
\frac{\mathrm{d} q_{t}}{\mathrm{~d} t}=k_{2}\left(q_{e}-q_{t}\right)^{2} .
$$

The integration of the Eq. (5) with the initial condition, $q_{t}=0$ at $t=0$ leads to linear Eq. (6) as follows:

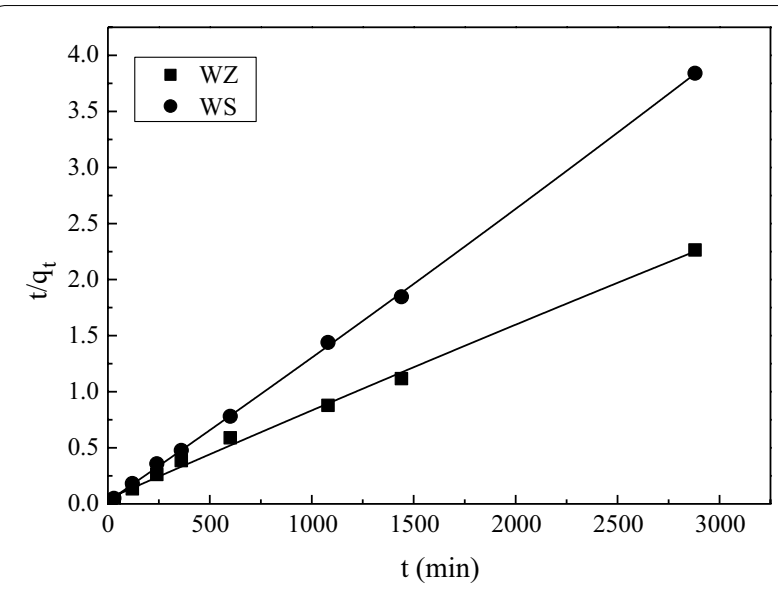

Fig. 3 Linearized pseudo-second-order kinetic model for atrazine adsorption in different soil samples

Table 4 Kinetic parameters for atrazine adsorption in soils

\begin{tabular}{|c|c|c|c|}
\hline \multirow[t]{2}{*}{ Kinetic models } & \multirow[t]{2}{*}{ Parameters } & \multicolumn{2}{|c|}{ Soil samples } \\
\hline & & WZ & ws \\
\hline \multirow{2}{*}{$\begin{array}{l}\text { Pseudo-second- } \\
\text { order kinetic model }\end{array}$} & $k^{2}\left(\mathrm{~kg}(\operatorname{mg} \min )^{-1}\right)$ & 0.0489 & 0.0782 \\
\hline & $R^{2}$ & 0.9997 & 0.9986 \\
\hline \multirow{3}{*}{$\begin{array}{l}\text { Weber-Morris intra- } \\
\text { particle diffusion } \\
\text { model }\end{array}$} & $\mathrm{kp}\left(\mathrm{mg}\left(\mathrm{kg} \mathrm{min} \mathrm{n}^{0.5}\right)^{-1}\right)$ & 0.14 & 0.05 \\
\hline & $c\left(\mathrm{mg} \mathrm{kg}^{-1}\right)$ & 14.01 & 10.64 \\
\hline & $R^{2}$ & 0.8081 & 0.5958 \\
\hline
\end{tabular}

$$
\frac{t}{q_{t}}=\frac{1}{k_{2} q_{e}^{2}}+\frac{t}{q_{e}}
$$

where $q_{t}$ is the adsorption capacity of atrazine at time $t$ $\left(\mathrm{mg} \mathrm{kg}^{-1}\right) ; k_{2}$ is the pseudo-second-order reaction rate constant $\left(\mathrm{kg}(\mathrm{mg} \mathrm{min})^{-1}\right) ; q_{e}$ is the amount of atrazine $\left(\mathrm{mg} \mathrm{kg}^{-1}\right)$ adsorbed by soils at equilibrium.

The linearized pseudo-second-order kinetic model of atrazine adsorption to soil and the assessed parameters are presented in Fig. 3 and Table 4. According to the fitting correlation coefficient $\left(R^{2}\right)$, the pseudo-second-order kinetic model exhibited good consistency with experimental data and could describe the dynamic processes of atrazine adsorption in both soils, with $R^{2}$ values almost equal to 1 for both soil samples. This indicates that the adsorption behavior of atrazine is obvious and that the rate during the adsorption process is controlled by chemical processes $[58,59]$. The pseudo-second-order kinetic model covers all processes of adsorption, such as external liquid film diffusion, internal particle diffusion and surface adsorption, among others [42], which can reflect the adsorption mechanism of atrazine in soil more accurately and comprehensively. 
Generally, the adsorption kinetics of particles or molecules onto the surface of soils mainly includes two phases of transport and attachment separation [59-61]. The transport of particles is based on diffusion, which is caused by the attraction of the surface to the adsorbate [62]. However, the pseudo-second-order kinetic model does not identify the diffusion mechanism of atrazine soil adsorption.

Therefore, to better understand the factors affecting adsorption kinetics, the Weber-Morris intraparticle diffusion model [39] was applied to simulate experimental data, which was calculated according to Eq. (7) as follows:

$$
q_{t}=k_{\mathrm{id}} t^{0.5}+c,
$$

where $k_{\text {id }}\left(\mathrm{kg}\left(\mathrm{mg} \mathrm{min}{ }^{0.5}\right)^{-1}\right)$ is the intraparticle diffusion rate constant; and $c$ is a constant.

The linearized Weber-Morris intra-particle diffusion kinetic model and its parameters for atrazine sorption in soils are depicted in Table 3. According to previous studies, $q_{t}$ and $t^{0.5}$ in the interparticle diffusion model exhibit a linear relationship. Based on the intercept through the origin point, results indicated that the interparticle diffusion process of substances is not the only control step for adsorption rate, with other mechanisms potentially playing an important role [41, 59, 63, 64]. From Fig. 4 and parameters in Table 3, it was found that the linear relationship between $q_{t}$ and $t^{0.5}$ was not reasonable and that plots do not pass through the point of origin. This indicates that the intragranular diffusion process of atrazine was not the main control process of adsorption in both soils. The adsorption process involves a certain degree of boundary layer control and the adsorption rate is also affected by extragranular diffusion processes, such as surface adsorption and liquid film diffusion $[41,42,59]$.

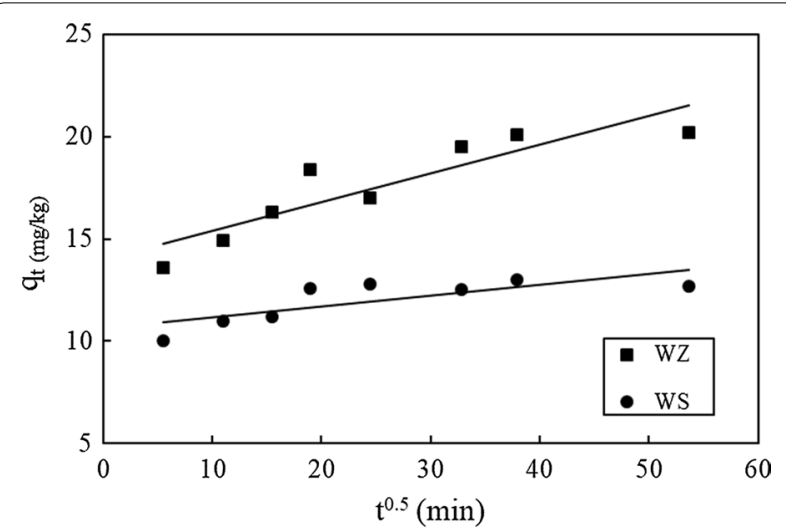

Fig. 4 Intra-particle diffusion model describing the adsorption of atrazine by two soil samples

\section{Thermodynamic parameters of adsorption}

Thermodynamic parameters help to describe the energy changes involved in the adsorption process [41]. To clarify the adsorption mechanism of atrazine in soil, the adsorption status of atrazine at different temperatures $(288,298$ and $308 \mathrm{~K})$ was analyzed and the influence of temperature on the equilibrium adsorption coefficient was assessed based on the standard Gibbs free energy $\left(\Delta r G_{m}^{0}\right)$ formula (Eq. (8)). Furthermore, the relevant thermodynamic parameters of standard enthalpy $\left(\Delta \mathrm{r} H_{m}^{0}\right)$, and standard entropy $\left(\Delta r S_{m}^{0}\right)$ were calculated using Eq. (9) as follows [59]:

$$
\begin{aligned}
& \Delta r G_{m}^{0}=-\mathrm{RT} \ln K_{0}, \\
& \ln K_{0}=-\frac{\Delta \mathrm{r} H_{m}^{0}}{\mathrm{RT}}+\frac{\Delta r S_{m}^{0}}{R},
\end{aligned}
$$

where $K_{0}$ is the adsorption equilibrium constant; $R$ is the gas molar constant $\left(8.314 \mathrm{~J}(\mathrm{~mol} \mathrm{~K})^{-1}\right)$; and $T$ is absolute temperature. According to the slope and intercept of the plot $\ln K_{0}$ versus $1 / T$, the values of $\Delta r S_{m}^{0}$ and $\Delta \mathrm{r} H_{m}^{0}$ were obtained.

In general, the $\Delta r G_{m}^{0}$ represents the spontaneity of the chemical reaction and is used to evaluate whether the adsorption reaction occurs spontaneously $[27,65]$. The thermodynamic parameters of atrazine adsorption by the two soils are shown in Table 5 , with values of $\Delta r G_{m}^{0}$ being $<0$, indicating the sorption of atrazine by soils was spontaneous. The ranked order of the absolute values for atrazine absorption by soil at different temperatures was as follows: $\Delta r G_{m 298 \mathrm{~K}}^{0}>\Delta r G_{m}^{0} 308 \mathrm{~K}>\Delta r G_{m}^{0} 318$ $\mathrm{K}$. The adsorption of atrazine in the soil increased with the increase in temperature, indicating adsorption at higher temperatures was easier than at low temperatures. It is generally believed that when the values of $\Delta r G_{m}^{0}$ are between 0 and $-20 \mathrm{~kJ} \mathrm{~mol}^{-1}$, physical adsorption is occurring with van der Waals forces playing a dominant role, resulting in the adsorption effect being small and desorption occurring easily. When the values of $\Delta r G_{m}^{0}$ are between -80 and $-400 \mathrm{~kJ} \mathrm{~mol}^{-1}$, chemical adsorption

\begin{tabular}{|c|c|c|c|c|}
\hline Samples & $T$ & $\begin{array}{l}\Delta r G_{m}^{0} \\
\left(k J \mathrm{~mol}^{-1}\right)\end{array}$ & $\begin{array}{l}\Delta r S_{m}^{0} \\
\left(\mathrm{~J}(\mathrm{~mol} \mathrm{~K})^{-1}\right.\end{array}$ & $\Delta \mathrm{r} H_{m}^{0}\left(\mathrm{~kJ} \mathrm{~mol}{ }^{-1}\right)$ \\
\hline \multirow[t]{3}{*}{ Soil (Wanzhou) } & 288 & -0.849 & 16.9 & -5.38 \\
\hline & 298 & -0.598 & & \\
\hline & 308 & -0.418 & & \\
\hline \multirow[t]{3}{*}{ Soil (Wushan) } & 288 & -0.794 & 28.7 & -9.27 \\
\hline & 298 & -0.309 & & \\
\hline & 308 & -0.222 & & \\
\hline
\end{tabular}

Table 5 Thermodynamic parameters for sorption of atrazine onto soils at different temperatures 
is occurring with chemical bonding playing a dominant role, resulting in a larger adsorption energy and a higher tendency for irreversible adsorption $[41,66]$. In this study, the values of $\Delta r G_{m}^{0}$ were between -0.418 and $-0.849 \mathrm{~kJ} \mathrm{~mol}^{-1}$ for Wanzhou soil and between -0.222 and $-0.794 \mathrm{~kJ} \mathrm{~mol}^{-1}$ for Wushan soil indicating that the adsorption of atrazine by both soil samples occurred by physical adsorption and confirming that the adsorption of the atrazine by soil is feasible and spontaneous.

The standard enthalpy changes $\left(\Delta \mathrm{r} H_{m}^{0}\right)$ for the adsorption of atrazine in WanZhou and WuShan soils were -5.38 and $-9.27 \mathrm{~kJ} \mathrm{~mol}^{-1}$, respectively. The value of $\Delta \mathrm{r} H_{m}^{0}$ was less than 0 , indicating that the solid phase of atrazine adsorbed from water to the soils was via an exothermic process, releasing large amounts of heat [67]. This result showed that adsorption was mainly based on physical properties, which is consistent with the results of $\Delta r G_{m}^{0}$. Studies have previously reported that when the standard enthalpy ranges from 40 to $120 \mathrm{~kJ} \mathrm{~mol}^{-1}$, adsorption occurs via a chemical process; otherwise, adsorption is via physical processes [68]. Therefore, the adsorption of the atrazine in this study appeared seems to occur via physical sorption. The standard entropy changes $\left(\Delta r S_{m}^{0}\right)$ of the adsorption of atrazine in Wanzhou and Wushan were 16.9 and $28.7 \mathrm{~J}(\mathrm{~mol} \mathrm{~K})^{-1}$, respectively. The positive values of $\Delta r S_{m}^{0}$ indicate that soils had an affinity for atrazine and also reflect changes in the structures of atrazine and soils. In addition, the positive $\Delta r S_{m}^{0}$ value indicated that randomness of the solid-liquid interface increased during the adsorption process.

\section{Conclusions}

The effects of temperature and contact time on the adsorption of atrazine in the two soils (Wanzhou and Wushan) of the Three-Gorges Reservoir were investigated, showing that adsorption was favorable. Within the range of initial concentration variation, the adsorption of atrazine by soil decreased with increasing temperature (298-318 K). The atrazine adsorption data for both soil samples could be fitted by the Freundlich and Langmuir models, indicating that single-layer adsorption may occur, with heterogeneous active site energy distribution on the soil surface. The adsorption of atrazine can be described by the pseudo-second-order model and internal particle diffusion was found not to be the only ratecontrolling step. As the adsorption time progressed, the amount of adsorbed atrazine in the soil increased gradually, indicating that the high initial concentration solution can provide sufficient power for mass transfer resistance between the atrazine molecular reduction solution and the adsorbent. During the adsorption of atrazine in soils, $\Delta r G_{m}^{0}<0, \Delta \mathrm{r} H_{m}^{0}<0$ and $\Delta r S_{m}^{0}>0$, indicating that the adsorption process is a spontaneous exothermic process and that the degree of chaos in the whole adsorption process increased. Generally, the adsorption capacity was low, indicating that atrazine can easily penetrate the soil vadose zone to pollute groundwater. Therefore, much attention should be paid to the environmental behavior of pesticide exposed soil moisture fluctuations, leading to the potential broad transport of pollution.

\section{Acknowledgements}

The valuable comments of Professor Limin Ma are acknowledged.

\section{Authors' contributions}

$H Y, X S, Y L, X S$ and HF performed the experiments. HY wrote the manuscript. LM and YP contributed to the manuscript correction. All authors read and approved the final manuscript.

\section{Funding}

This work was supported by the National Key R\&D Program of China (2018YFC1803100) and National Natural Science Foundation of China (No. 21377098).

\section{Availability of data and materials}

The data sets supporting the conclusions of this article are included within the article.

\section{Ethics approval and consent to participate}

Not applicable.

\section{Consent for publication}

Not applicable.

\section{Competing interests}

The authors declare that they have no competing interests.

\section{Author details}

${ }^{1}$ College of Environmental Science and Engineering, Tongji University, Shanghai 200092, China. ${ }^{2}$ College of Biology and the Environment, Nanjing Forestry University, Nanjing 210037, China. ${ }^{3}$ Shanghai Institute of Pollution Control and Ecological Security, Shanghai 200092, China.

Received: 6 December 2019 Accepted: 9 February 2020

Published online: 26 February 2020

\section{References}

1. Tang JS, Chen WW, Ju HX (2019) Sensitive surface-enhanced Raman scattering detection of atrazine based on aggregation of silver nanoparticles modified carbon dots. Talanta 201:46-51

2. de Oliveira LA, Honorio DJ, Grecco KL, Tornisielo VL, Woodbury BL (2019) Atrazine movement in corn cultivated soil using HYDRUS-2D: a comparison between real and simulated data. J Environ Manage 248:109311

3. Du Preez LH, van Rensburg PJJ, Jooste AM, Carr JA, Giesy JP, Gross TS, Kendall RJ, Smith EE, Van Der Kraak G, Solomon KR (2005) Seasonal exposures to triazine and other pesticides in surface waters in the western Highveld corn production region in South Africa. Environ Pollut 135:131-141

4. Shan RF, Chen Y, Meng LC, Li HY, Zhao ZQ, Gao MZ, Sun XY (2020) Rapid prediction of atrazine sorption in soil using visible near-infrared spectroscopy. Spectrochim Acta Part A Mol Biomol Spectrosc 224:117455

5. Sun K, Gao B, Zhang ZY, Zhang GX, Zhao Y, Xing BS (2010) Sorption of atrazine and phenanthrene by organic matter fractions in soil and sediment. Environ Pollut 158:3520-3526

6. Si YB, Meng XM (2007) Advance in environmental fate and ecological remediation of the herbicide atrazine. J Anhui Agric Univ 34:451-455

7. Vonberg D, Vanderborght J, Cremer N, Pütz T, Herbst M, Vereecken H (2014) 20 years of long-term atrazine monitoring in a shallow aquifer in western Germany. Water Res 50:294-306 
8. Salazar-Ledesma M, Prado B, Zamora O, Siebe C (2018) Mobility of atrazine in soils of a wastewater irrigated maize field. Agroecosyst Environ 255:73-83

9. 2004/248/EC, 2004. Commission Decision of 10 March 2004 concerning the non-inclusion of atrazine in Annex I to Council Directive 91/414/ EEC and the withdrawal of authorisations for plant protection products containing this active substance. Off. J.Eur. Union L078, 53-55 16/03/2004

10. Sousa JCG, Ribeiro AR, Barbosa MO, Pereira MFR, Silva AMT (2018) A review on environmental monitoring of water organic pollutants identified by EU guidelines. J Hazard Mater 344:146-162

11. Lima DLD, Silva CP, Schneider RJ, Esteves VI (2011) Development of an ELISA procedure to study sorption of atrazine onto a sewage sludgeamended luvisol soil. Talanta 85:1494-1499

12. Lin KY, Chu W (2011) Simulation and quantification of the natural decay of a typical endocrine disrupting chemical atrazine in an aquatic system. J Hazard Mater 192:1260-1266

13. Jablonowski ND, Schäfferand A, Burauel P (2011) Still present after all these years: persistence plus potential toxicity raise questions about the use of atrazine. Environ Sci Pollut Res 18:328-331

14. Sun XY, Liu F, Shan RF, Fan YN (2019) Spatiotemporal distributions of $C u$, $\mathrm{Zn}$, metribuzin, atrazine, and their transformation products in the surface water of a small plain stream in eastern China. Environ Monit Assess 191:7

15. Chladna Z (2007) Determination of optimal rotation period under stochastic wood and carbon prices. For Policy Econ 9:1031-1045

16. Lima DLD, Schneider RJ, Scherer HW, Duarte AC, Santos EBH, Esteves VI (2010) Sorption-desorption behavior of atrazine on soils subjected to different organic long-term amendments. J Agric Food Chem 58:3101-3106

17. Sanchez V, Francisco, Lopez-Bellido J, Rodrigo MA, Rodriguez L (2019) Enhancing the removal of atrazine from soils by electrokinetic assisted phytoremediation using ryegrass (Lolium perenne L.). Chemosphere 232:204-212

18. Huang YF, Liu ZZ, Wei L, Li YL, Huang LX, Huang Q, Xu GZ (2018) Effects of amorphous Fe oxides on adsorption-desorption of atrazine in soil. Acta Pedol Sin 55:148-158

19. Katz H, Mishael YG (2014) Reduced herbicide leaching by in situ adsorption of herbicide-micelle formulations to soils. J Agric Food Chem 62:50-57

20. Kaur P, Makkar A, Kaur P, Shilpa (2017) Temperature dependent adsorption-desorption behaviour of pendimethalin in punjab soils. Bull Environ Contam Toxicol 100:167-175

21. Wu QQ, Yang Q, Zhou WJ, Zhu LZ (2015) Sorption characteristics and contribution of organic matter fractions for atrazine in soil. J Soils Sediments 15:2210-2219

22. Yang F, Zhang SS, Sun LL, Zhang Y (2018) Facile synthesis of highly porous "carbon sponge" with adsorption and co-adsorption behavior of lead ions and atrazine. Environ Sci Pollut Res 25:1-12

23. Yang X, Cheng K, Jia GZ (2018) Molecular dynamics simulation of temperature-dependent atrazine aqueous solution. J Mol Liq 256:456-461

24. Yang WC, Wang QQ, Liu WP (2000) Adsorption of herbicide atrazine on soils. Environ Sci 21:94-97

25. Baez ME, Fuentes E, Espinoza J (2013) Characterization of the atrazine sorption process on andisol and ultisol volcanic ash-derived soils: kinetic parameters and the contribution of humic fractions. J Agric Food Chem 61:6150-6160

26. Jiang YF, Mu ZF, Uwamungu JY, Sun H, Hu XF, Zhan HY, Liu PY (2016) Study on the adsorption behavior of atrazine onto loess soil in Northwest China. Res Environ Sci 29:547-552

27. Li FZ, Feng D, Deng H, Yu HM, Ge CJ (2015) Adsorption and desorption of atrazine in five agriculture soils. Ecol Environ Sci 24:2056-2061

28. Liu YH, Xu ZZ, Wu XG (2010) Adsorption and desorption behavior of herbicide diuron on various Chinese cultivated soils. J Hazard Mater 178:462-468

29. Delle Site A (2001) Factor affecting sorption of organic compound in natural sorbent/water systems and sorption coefficients for selected pollutants. A review. J Phys Chem Ref Data 30:87-439

30. Kodesova R, Kocarek M, Kodes V, Drabek O, Kozak J, Hejtmankova K (2011) Pesticide adsorption in relation to soil properties and soil type distribution in regional scale. J Hazard Mater 186:540-550

31. Boivin A, Cherrier R, Schiavon M (2005) A comparison of five pesticides adsorption and desorption processes in thirteen contrasting field soils. Chemosphere 61:668-676
32. Reilley A, Banks MK, Schwab AE (1996) Dissipation of PAHs in the rhizosphere. J Environ Qual 25:212-219

33. Miya RK, Firestone MK (2000) Phenanthrene—Degrader community dynamics in rhizosphere soil from a common annual grass. J Environ Qual 29:584-592

34. Niu Z, Xie M (1998) Thoughts on development and utilization of water and soil resouces in the reservoir changing region in the Three Gorges Reservoir area. Sci Technol Rev 4:61-62

35. Bao SD (2000) Soil agrochemical analysis. China Agriculture Press, Beijing

36. McCarty PL, Reinhard M, Rittmann BE (1981) Trace organics in groundwater. Environ Sci Technol 15:40-51

37. Spark KM, Swift RS (2002) Effect of soil composition and dissolved organic matter of pesticide sorption. Sci Total Environ 298:147-161

38. Wang P, Keller AA (2009) Sorption and desorption of atrazine and diuron onto water dispersible soil primary size fractions. Water Res 43:1448-1456

39. Weber WJ Jr, McGinley PM, Katz PM (1992) A distributed reactivity model for sorption by soils and sediments. 1.Conceptual basis and equilibrium assessments. Environ Sci Technol 26:1955-1962

40. Kasozi GN, Nkedi-Kizza P, Lib Y, Zimmerman AR (2012) Sorption of atrazine and ametryn by carbonatic and non-carbonatic soils of varied origin. Environ Pollut 169:12-19

41. Zhang JY, Wu CD, Jia AY et al (2014) Kinetics, equilibrium, and thermodynamics of the sorption of p-nitrophenol on two variable charge soils of Southern China. Appl Surf Sci 298:95-101

42. Chang MY, Juang RS (2004) Adsorption of tannic acid, humic acid, and dyes from water using the composite of chitosan and activated clay. J Colloid Sci 278:18-25

43. Deng JC, Jiang X, Hu WP, Lu X (2007) Effect of sorption reaction time on behavior of herbicide atrazine. Ecol Environ 16:402-406

44. Schwarzenbach RP, Gschwend PM, Imboden DM (1993) Environmental organic chemistry. Wiley, Hoboken

45. Langmuir I (1918) The adsorption of gases on plane surfaces of glass, mica and platinum. J Am Chem Soc 40:1361-1403

46. Cooney DO (1999) Adsorption design for wasterwater treatment. Lewis Publishers, Boca Raton

47. Sahu MK, Mandal S, Yadav LS, Dash SS, Patel RK (2016) Equilibrium and kinetic studies of $\mathrm{Cd}(\mathrm{II})$ ion adsorption from aqueous solution by activated red mud. Desalin Water Treat 57:14251-14265

48. Freundlich HMF (1906) Über die adsorption in lösungen. Z Phys Chem $57: 385-470$

49. Sun J, Ma XL, Wang W, Zhang J, Zhang H, Wang YJ, Feng J (2019) The adsorption behavior of atrazine in common soils in Northeast China. Bull Environ Contam Toxicol 103:316-322

50. Mckay G, Blair HS, Gardener JR (1982) Adsorption of dyes on chitin. 1. Equilibrium studies. J Appl Polym Sci 27:3043-5307

51. Chowdhury S, Das Sala P (2011) Biosorption kinetics, thermodynamics and isosteric heat of sorption of Cu (II) onto Tamarindus indica seed powder. Colloids Surf B 88:697-705

52. Fasfous II, Dawoud JN (2012) Uranium (VI) sorption by multiwalled carbon nano-tubes from aqueous solution. Appl Surf Sci 259:433-440

53. Lladó J, Lao-Luque C, Ruiz B, Fuente E, Dorado AD, Solé-Sardans Montserrat M (2015) Role of activated carbon properties in atrazine and paracetamol adsorption equilibrium and kinetics. Process Saf Environ Prot 95:51-59

54. Lupul I, Yperman J, Carleer R, Gryglewicz G (2015) Adsorption of atrazine on hemp stem-based activated carbons with different surface chemistry. Adsorp J Int Adsorp Soc 21:489-498

55. Xing BS, Pignatello JJ (1996) Time-dependent isotherm shape of organic compounds in soil organic matter: implications for sorption mechanism. Environ Toxicol Chem 15:1282-1288

56. Ye CM, Lei ZF, Wang XJ, Gong AJ, Zheng HH (2001) Multimedia environmental behaivor of herbicide atrazine. Environ Sci 22:69-73

57. Karapanagioti HK, Kleineidam S, Sabatini DA, Grathwohl P, Ligouis B (2000) Impacts of heterogeneous organic matter on phenanthrene sorption: equilibrium and kinetic studies with aquifer material. Environ Sci Technol 34:406-414

58. Ho YS, McKay G (1999) Pseudo-second order model for sorption process. Process Biochem 34:451-465

59. Fu QL, Deng YL, Li HS, Liu J, Hu HQ, Chen SW, Sa TM (2009) Equilibrium, kinetic and thermodynamic studies on the adsorption of the toxins 
of Bacillus thuringiensis subsp. kurstaki by clay minerals. Appl Surf Sci 255:4551-4557

60. Baret JF (1968) Kinetics of adsorption from a solution. role of the diffusion and of the adsorption desorption antagonism. J Phys Chem 72:2755-2758

61. Dukhin SS, Kretzmar G, Miller R (1995) Dynamics of adsorption at liquid interfaces: theory, experiment, application. Elsevier, Amsterdam

62. Koopal LK, Avena MJ (2001) A simple model for adsorption kinetics at charged solid-liquid interfaces. Colloids Surf A 192:93-107

63. Nassar MM (1999) Intraparticle diffusion of basic red and basic yellow dyes on palm fruit bunch. Water Sci Technol 40:133-139

64. Hameed BH (2007) Equilibrium and kinetic studies of 2,46-tichlorophenol adsorption onto activated clay. Colloids Surf A 307:45-52

65. Saha P, Chowdhury S (2011) Insight into adsorption thermodynamics (Chap. 16). In: Tadashi M (ed) Thermodynamics. InTech, pp 349-364
66. Liu Y (2009) Is the free energy change of adsorption correctly calculated? J Chem Eng Data 54:1981-1985

67. Wei X, Wu Z, Wu Z, Ye BC (2018) Adsorption behaviors of atrazine and $\mathrm{Cr}(\mathrm{III})$ onto different activated carbons in single and cosolute systems. Powder Technol 329:207-216

68. Alkan M, Demirbas O, Celikcapa S, Dogan M (2004) Sorption of acid red 57 from aqueous solution onto sepiolite. J Hazard Mater 116:135-145

\section{Publisher's Note}

Springer Nature remains neutral with regard to jurisdictional claims in published maps and institutional affiliations.

\section{Submit your manuscript to a SpringerOpen ${ }^{\circ}$ journal and benefit from:}

- Convenient online submission

- Rigorous peer review

- Open access: articles freely available online

- High visibility within the field

- Retaining the copyright to your article

Submit your next manuscript at $\boldsymbol{\nabla}$ springeropen.com 